\title{
Narrative gerontology and digital storytelling: what benefits for elders?
}

\begin{abstract}
The well-being of the aging population is a current and growing concern. We have explored two different ways which, if combined, seem to be a new promising concept. Narrative gerontology is credited with bringing many benefits and improving the feeling of "wellbeing" of the elders through intergenerational sharing, and thus, allowing a "well-aging". Digital storytelling, through sound, image and music, tells a biography in a few minutes that can be shared with an intimate or as many as the whole wired world. Thereby, by combining narrative gerontology and digital storytelling to create "digital narrative gerontology", we wish to bring a new promoter concept which will act positively on the "well-being" of the elders, on their "well-aging" and share these positive values with the community.
\end{abstract}

Keywords: narrative gerontology, digital storytelling, intergenerational, welfare, learning
Volume 6 Issue 6 - 2017

\author{
Beatrice Crettenand Pecorini, Emmanue \\ Duplaa
}

Faculty of Education, University of Ottawa, Canada

Correspondence: Beatrice Crettenand Pecorini, Student MA in Education, Health Professions Education concentration, 145 Jean-Jacques-Lussier Private, LMX3 | 4, Canada, Tel 613-5625800 (4635),Email bcret075@uottawa.ca

Received: June 30, 2017 | Published: December 13, 2017

\section{Introduction}

Between 2000 and 2050, the proportion of the world's population over 60years will double from about $11 \%$ to $22 \% .{ }^{1}$ In Canada, for the first time in 2015, the number of people aged 65 and over has exceeded that of children aged 0 to 14 years. ${ }^{2}$ When we think of the elderly, we inevitably associate it with age-related health problems. Approximately 75 to $80 \%$ of Canadian seniors report having at least one chronic condition. ${ }^{3}$ Lafreniere ${ }^{4}$ recognizes that a person who has a disease can at the same time is healthy: well-being is a way of living and developing. Well-being is therefore important in the definition of health, not in the sense of not being sick, but in living well, even with one or more diseases. In the elderly, in addition to well-being, well-aging is also important. In their $18-$ year study, Windsor TD ${ }^{5}$ concluded that seniors with a higher sense of purpose experience better aging and increased longevity. It would therefore be beneficial to inspire seniors to find a sense of purpose in their lives. There are many possible ways to explore in order to achieve this goal. If we wanted to highlight well-being, well-aging and sense of purpose in the elderly, it is because these concepts are found in narrative gerontology, which could be a way to develop improving seniors' life quality. We will also explore how the benefit of narrative gerontology can be shared with digital storytelling and be beneficial not only for the storyteller and the collector, but also for all listeners. This work is the first step of a MA research project supported by AGE-WELL NCE Inc., which the goal is to increase elderly health and education.

\section{Discussion}

\section{Narrative gerontology}

Narrative gerontology is a process where the elderly person (gerontology) tells the history of his life (narration), a sort of retrospective of his life. The specificity of narrative gerontology exists in the inter-generational dynamics between the storytellerthe elderly person-and the story collector (of a younger generation), through informal learning for both parties and providing the elder a strategy for a "better aging". ${ }^{6}$ Guillemot et al. ${ }^{7}$ describe 6 intrinsic motivations for narration among the elderly that we can relate to narrative gerontology: a. Flattering ego (self-confidence, achievement);

b. Repairing the ego (to heal, resilience);

c. Not being forgotten (trans-generational);

d. Sharing (education, learning);

e. To transmit (valorization, meaning to life);

f. To testify (to remember, to communicate, to resilience).

All these intrinsic motivations can be used to highlight individual resilience (and community resilience when shared) and personal and mutual learning during narrative gerontology. Grimm et al. ${ }^{8}$ also conclude from their study that life review by elderly people can contribute to improved quality of life. Narrative gerontology contributes above all to the health of the storyteller by his well-being in the narrative of his life, thus improving his life quality; But it is also an inter-generational trainer through its exchange with the collector (listener), being a historical and social source and, consequently, a vector of improvement of the community health. ${ }^{6}$ The common project of the biography is the starting link between the storyteller and the collector. The collector not only provides an attentive ear but also stimulates the narrative. The narrative of the elders differs from that of the younger generations because their perspective of life is different. Seniors are very comfortable with dialectical thinking, ${ }^{9}$ which is a wealth of narrative interviews.

A bias may appear as the narration progresses, as the storyteller and the collector become more and more intimate with each other. There is the risk that the storyteller will "suppress" or soften a passage of his life depending on the listener-collector, for example if the storyteller is a man and the collector is a young woman, ${ }^{10}$ suffers an ethical dilemma between proximity of the collector and distance of the researcher (if the collector is also a researcher), ${ }^{11}$ or that the collector did not critically analyze his own role in conducting the interview, his personal values, and his attitudes toward seniors. ${ }^{12}$ The same authors note that the age, maturity and life experience of the collector also influence the fluidity of the narration. The collector requires solid tools and self-awareness (humility, attention, sincere interest, non-judgment, empathy - while maintaining an attitude of benevolent neutrality, respect, being able to receive emotions) before starting the narrative interviews. ${ }^{6}$ Another 
difficulty may arise: the narrator, to remember his accomplishments, his failures, his despair, must put words on emotions and share them. ${ }^{8}$ One of the risks is to recall painful memories during the narrative interviews and to provoke negative emotional states in the narrator. We must therefore be aware of this risk and surround ourselves with professionals to respond to any significant emotional distress. But narration also brings other values and benefits: the narrative links generations, transmits knowledge, values and a sense of shared identity. In addition, Andrews $\mathrm{GJ}^{13}$ note the significant contribution of oral history to the discipline of history. The most important for us, narrative, especially narrative gerontology, brings many other benefits: well-being, resilience, wisdom, spirituality, well-aging, inter-generational links, informal learning, enrichment of cultural and historical heritage. ${ }^{6-13}$

\section{Digital storytelling}

To date, the life stories collected during narrative gerontology have most often been transcribed in the form of a text, a photo montage, an artwork made up of objects meaningful to the storyteller, or oral recordings. In order to bring a new dimension to the narrative gerontology, we want to associate it with digital storytelling. We call it Digital Narrative Gerontology. "Digital storytelling applies moving visual images, text, graphics, and audio components that produce a multimedia product for new or 'remixed' versions of stories". ${ }^{14}$ The digital story is usually two to five minutes in length and told in the first person. Much work is needed to reduce the story of a lifetime in a few minutes. For digital narrative gerontology, this work is carried out by two people, one of whom tells and another who listens, two people of different generations, with different skills and knowledge, different values and life experiences and different life expectancy. The listener shows interest in the senior by reminding him or her, that the storyteller is a person in his or her own right, who contributes to something, creates, communicates and shares. All this work of recounting, remembering, creating and sharing not only promotes a sense of well-being for the storyteller but also to the listener and future audiences. Loe ${ }^{15}$ conducted a study through the Digital Life History Project which matched community-dwelling elderly people and young adults (19-20years) who together created a digital story honoring the elder's life. She notes a wealth of profit in the common creation and sharing of life stories as common humanity, civic engagement, and older learning partners guiding young adults towards self-awareness, newfound interest in historical events and diminished fear of aging. A fairly similar project was conducted by Hewson $\mathrm{J}^{16}$ over a period of five days.

They also come to the conclusion that inter-generational sharing is educational at many levels, resulting in the creation of a product that can be used in multiple ways, such as teaching, advocacy and communication but also as a new way to integrate seniors into the post-secondary curriculum and better prepare young practitioners to work with elderly people. We give an important place to the seniors who are no longer relegated to a passive role, they are valued for their greater well-being, and they have a sense of purpose. Seniors may not be familiar with digital technologies, but the association of two generations, as in narrative gerontology, makes it possible to fill in any gaps. Manchester et al., ${ }^{17}$ in their article, looked at the powerful capabilities of digital technologies, which are under-used by the seniors, meaning that their cultural stories and their experiences are often less accessible in the digital world. They draw three important points in their conclusion: motivation is inter-generational in the sharing and transfer of knowledge; Discussions and exchanges, sharing of archives was just as important as digitization; And the last point that has all its importance in digital storytelling with seniors are ethical issues, the elders underestimating the consequences of publishing their story. This last point is also highlighted by the "StoryCenter" in Berkeley (USA), which has been specialized since 1993 in digital storytelling: "As field leaders, our recommendations for ethical practice in Story Work ensure the safety and dignity of storytellers and audiences worldwide". ${ }^{18}$

\section{Links, benefits and challenges}

There are no studies that have linked narrative gerontology and digital storytelling. We have on one side the evaluated and studied benefits of narrative gerontology and on the other the advantages of inter-generational digital storytelling. The benefits of digital storytelling have been studied more carefully on the side of younger generations, without taking into account the impact (supposedly positive) on older generations. We would like to confirm the benefits of the narrative gerontology for seniors, but also assess the impact on the well-being, well-aging and resilience of elderly people after the common digitization of their life story, and secondly, after the broadcast of their digital storytelling, both on themselves and on the younger generations. This narrative gerontology project associated with digital storytelling should develop new skills through learning and create new resources for wellness and health. By learning, we think about the acquisition and development of new skills (technical, ethical, relational, communication) by mutual learning-thus inter-generational-between the storyteller and the collector; The dissemination of digital storytelling which will in turn enable an expanded inter-generational audience to acquire new and important educational knowledge through the storyteller's life experience; and by contributing to a better understanding of the elders, their problems but also and especially their wealth of knowledge. For health and well-being, we think that through its narration to others, the storyteller will feel important, recognized, useful, motivated and active, which will strengthen his assertiveness and self-esteem, and therefore his well-being; Through the retrospective view on his life, the narrator can acquire serenity, balance, resilience, wisdom and well-being, which will influence his health; Through the sharing of a life story, experiences, roots of the past, traditions, values, etc. the community will have a new look at itself and will be more resilient. We issue the hypothesis that the benefits of the narrative gerontology will be reflected in the digital storytelling, both for "creator producers" and for "listener's viewers," with diminished effects on the latter.

Naturally, we cannot succeed as narrative collectors and even less as creators of digital storytelling without preparation. Upstream preparation is important and specific steps followed. The future collector must prepare his interviews, prepare himself to listen and also prepare the narrator.

1. Not only are specific skills required for the narration collection, such as narrative interviewing techniques, sound recording, discrete note taking, appropriate duration, number and location of appointments for the narration interview, but also appropriate attitudes, such as respect for the person, empathy, attentive listening, humility, interest for elders, respect for silence, commitment, non-judgment.

2. Knowledge related to digital storytelling is naturally of the order of digital technique, but also script writing and voice recording, image preparation and storyboarding, video editing and production. 
3. But a solid training is not enough if the collector-producer does not evaluate himself to understand his values and motivations, to ensure that he is transparent and neutral and that he identifies his presuppositions ${ }^{19}$ so as not to personally influence the narration as well as the creation of digital storytelling. Then, the collector can prepare the different steps to realize the digital narrative gerontology.

4. First, the ethical question arises. The collector will work with seniors, so it is very important to make clear all the issues of the narration as well as the diffusion of the digital storytelling (confidentiality, privacy, consequences, no reversal when published).${ }^{18}$ There is therefore a compulsory consent required that can be withdrawn at any time.

5. The choice of narrators is also important in relation to the collector. We must also take into account the generational, cultural, educational and linguistic differences between the narrator and the collector. For a good digital storytelling, we have to find seniors who are open to talk about their lives, but we must remain cognizant that not all biographies collected will result in beautiful and interesting digital storytelling. Harvesting archive photos is desirable to reinforce memories. ${ }^{13-20}$

6. Writing the script is an important step and can be difficult to achieve. It is necessary to motivate the narrator without influencing his narrative. It is his story and his way of telling, his way of seeing his life that we want to convey. When the script is written, we can record the voice of the narrator. This is not an obligation, but is common practice in digital storytelling.

7. The next step often requires substantial help from the collectorproducer. Images and music can be obtained from the storyteller's archives or found on the Net. What is imperative being to match the images and sounds to the narrator's idea? The addition of text such as titles or subtitles may be necessary.

8. Editing of the storytelling must respect the script and the narrator's intention. As a reminder, a digital storytelling lasts only two to five minutes.

9. The choice of whether or not to broadcast digital storytelling must be discussed again after the first viewing of the finished product. This can take place as a private broadcast for close family, a broadcast within a community, an association, a school or more broadly on the social media and the Net. Ultimately, the goal of this project is to evaluate the expected benefits.

10. The benefits of digital narrative gerontology must be explored in using semi-structured interviews, studied, analyzed and shared. Questions to be answered include as example: How did this project change your way of seeing your life? How did this project enable you to learn new things? How did you handle all your feelings during this project? What have you felt by recounting your life, seeing your life thus summed up? How did this project influence your well-being, your pride? How did you experience intergenerational sharing? There is a plethora of questions that should be asked to the narrator. But the collector will also testify to the changes he/she has witnessed, both for the narrator and for the collector (Table 1).
Table I Summary of data references of the benefits in narrative gerontology and digital storytelling.

\begin{tabular}{|c|c|c|c|c|}
\hline & & $\begin{array}{l}\text { Narrative } \\
\text { Gerontology }\end{array}$ & $\begin{array}{l}\text { Digital } \\
\text { Story } \\
\text { telling }\end{array}$ & \\
\hline \multirow{4}{*}{ Health } & Well-Being & $\begin{array}{l}\text { Ruchat } M^{6} \\
\text { Grimm Getal. }^{8} \\
\text { Randall W }^{10}\end{array}$ & $\begin{array}{l}\text { Loe } M^{15} \\
\text { Hewson J }\end{array}$ & \\
\hline & Well-Aging & $\begin{array}{l}\text { Ruchat } M^{6} \\
\text { Grimm Getal. }{ }^{8}\end{array}$ & & \\
\hline & Wisdom & Ruchat $M^{6}$ & Loe $M^{15}$ & \\
\hline & Resilience & $\begin{array}{l}\text { Randall } W^{10} \\
\text { Ruchat } M^{6} \\
\text { Grimm Getal. }\end{array}$ & & \\
\hline \multirow[t]{3}{*}{ Education } & 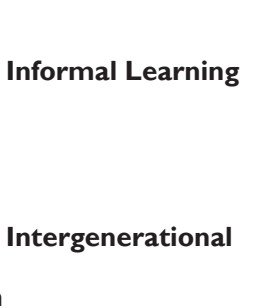 & Ruchat $M^{6}$ & 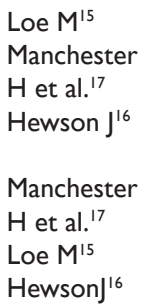 & $\begin{array}{l}\text { Intrinsic } \\
\text { Motivations } \\
\text { for } \\
\text { Narration } \\
\text { Guillemot S } \\
\text { et al. }{ }^{7}\end{array}$ \\
\hline & $\begin{array}{l}\text { Cultural and } \\
\text { historical Heritage }\end{array}$ & $\begin{array}{l}\text { Andrews GJ } \\
\text { Ruchat } M^{6}\end{array}$ & $\begin{array}{l}\text { Manchester } \\
\mathrm{H} \text { et al. }{ }^{17} \\
\text { Loe } \mathrm{M}^{15}\end{array}$ & \\
\hline & Ethic & & $\begin{array}{l}\text { Manchester } \\
\mathrm{H} \text { et al. }{ }^{17} \\
\text { Story } \\
\text { Center }^{18}\end{array}$ & \\
\hline
\end{tabular}

\section{Conclusion}

We are confident that the benefits of narrative gerontology associated with the benefits of digital storytelling will lead us to equally positive results with digital narrative gerontology. We therefore want to explore more precisely how narrative gerontology can be an educational source to be shared through digital storytelling with younger generations and beyond, for the health of the narrator and the community. The younger generation, with their ICT (information and communication technology) knowledge, could help in the design of digital storytelling created by seniors. We could imagine a high school/college/undergraduate education curriculum that includes digital storytelling training and who would be shared with seniors in an intergenerational approach. This approach can also be applied in different communities, such as Aboriginal people or societal groups, such as immigrants. The possibilities of using digital narrative gerontology are multiple. We all need well-being and the example of aging seniors with wisdom and serenity can only be an excellent testimony for younger generations. Finally, through this innovative social and community approach, we want to contribute to the health and well-being of seniors. There is undoubtedly still much work to be done in order to confirm our assumptions, but in the light of our research, we believe there is a real opportunity to improve seniors' sense of "well-being" with digital narrative gerontology and thus offer a "well-aging" with serenity. Happy aging, even sick or disabled, is what we can hope for all our elders and ourselves. 


\section{Acknowledgement}

This work is supported by AGE-WELL NCE Inc., a member of the Networks of Centres of Excellence program.

\section{Conflict of interest}

The authors have declared no financial/commercial conflict of interest.

\section{Funding}

None.

\section{References}

1. World Health Organization. Facts about ageing. Switzerland: World Health Organization; 2014.

2. Canada's population estimates, Canada: Age and sex Statistics. 2015.

3. HealthCare in Canada, 2011: A Focus on Seniors and Aging. Canada: Canadian Institute for Health Information; 2014. p. 1-162.

4. Lafreniere S. Promoting Seniors' Health: A Design Issue. Public health. 2004;16(2):303-312.

5. Windsor TD, Curtis RG, Luszcz MA. Sense of purpose as a psychological resource for aging well. Dev Psychol. 2015;51(7):975-986.

6. Ruchat M. Learning through the narrative biography: the generational effect in gerontagogical training. Gerontology and society. 2013;4: 49-61.

7. Guillemot S, Urien B. Legacy Writing among the Elderly: Conceptual Bases, Dimensioning and Proposed Scale for Measuring Motivations. Research and Applications in Marketing. 2010;25(4):25-43.

8. Grimm G, Boothe B. Narratives of life: Storytelling in the perspective of happiness and disaster. Journal of Aging, Humanities, and the Arts. 2007;1(3-4):137-146.
9. Lemieux A. Post-formal thinking in gerontagogy or post-Piaget. Journal of Behavioral and Brain Science. 2012;2(3):399-406.

10. Randall W, Baldwin C, McKenzie Mohr S, et al. Narrative and resilience: A comparative analysis of how older adults story their lives. Journal of Aging Studies. 2015;34:155-161.

11. Josselson R. The ethical attitude in narrative research: Principles and practicalities in handbook of narrative inquiry mapping a methodology. Chapter 21. USA: Thousand Oaks; 2007.

12. Feldman S, Howie L. Looking back, looking forward: reflections on using a life history review tool with older people. Journal of Applied Gerontology. 2009;28(5):621-637.

13. Andrews GJ, Kearns RA, Kontos P, et al. 'Their finest hour': older people, oral histories, and the historical geography of social life. Social \& Cultural Geography. 2006;7(2):153-177.

14. Hoechsmann M, De Waard H. Define digital literacy policy and practice in the landscape of Canadian education. Media Smarts, Canada. 2015;175 .

15. Loe M. The Digital Life History Project: Intergenerational Collaborative Research. Gerontol Geriatr Educ. 2013;34(1):26-42.

16. Hewson J, Danbrook C, Sieppert J. Engaging post-secondary students and older adults in an intergenerational digital storytelling course. Contemporary Issues in Education Research. 2015;8(3):135-142.

17. Manchester H, Facer K. Digital curation: Learning and legacy in later life. E-Learning and Digital Media. 2015;12(2):242-258.

18. Values and Methods. USA, StoryCenter: Listen Deeply_Tell stories; 2017.

19. Gohier C. The approach between scientific and ethical criteria in interpretive research. Qualitative research. 2004;24:3-17.

20. Bach H. Handbook of narrative inquiry mapping a methodology: Composing a visual narrative inquiry. chapter 11. USA:Thousand Oaks; 2007. 